\title{
Long-Term Improvement in Precautions for Flood Risk Mitigation: A Case Study in the Low-Lying Area of Central Vietnam
}

\author{
Cong Dinh Nguyen ${ }^{1,2} \cdot$ Fumikazu Ubukata $^{1} \cdot$ Quang Tan $^{\text {Nguyen }}{ }^{3} \cdot$ \\ Hoang Ha Vo ${ }^{2}$
}

Accepted: 11 December 2020/Published online: 7 January 2021

(C) The Author(s) 2021

\begin{abstract}
Local actors appear as inseparable components of the integrated flood risk mitigation strategy in Vietnam. Recognizing this fact, this study examined the long-term improvement in precautions taken by commune authorities and households between two major floods in 1999 and 2017 by applying both quantitative and qualitative methods. Two flood-prone villages were selected for a survey; one in a rural area and the other in a suburban area of Thua Thien Hue Province, central Vietnam. The findings indicate that most villagers doubted the structural works' efficacy and were dissatisfied with the current efforts of local authorities. Households' self-preparation thus became the decisive factor in mitigating risk. While most households have paid greater attention to flood precautions in 2017, others seem to be lagging. Poverty-related barriers were the root causes restraining households in both rural and suburban villages. The suburban riverine residents were further identified as vulnerable by their limitations in upgrading structural measures, which was ascribed to the inconsistency in the ancient town's preservation policy. This multidimensional comparison, in terms of vulnerability, emphasized the importance of space-function links in the suburb and the contradictions of different policy initiatives, such as landscape rehabilitation, disaster prevention, and livelihood maintenance.
\end{abstract}

Cong Dinh Nguyen

ncdinh@hce.edu.vn; nguyencongdinh@hueuni.edu.vn

1 Graduate School of Environmental and Life Science, Okayama University, Okayama 700-8530, Japan

2 Faculty of Economics and Development Studies, University of Economics, Hue University, Hue City 49000, Vietnam

3 International School, Hue University, Hue City 49000, Vietnam
Keywords Central Vietnam - Flood risk mitigation · Long-term improvement $\cdot$ Natural hazards $\cdot$ Precautionary measures

\section{Introduction}

It is widely recognized that natural hazard-related disasters have been steadily increasing across the planet over the last several decades (IPCC 2014). Notably, the frequency of floods has accelerated faster than any other type of disaster, leading to a tripling of major flood-related calamities since the 1980s (ADB 2013). Asia is the most disaster-afflicted region, accounting for nearly $62 \%$ of those who have experienced disasters and bearing approximately $70 \%$ of the total deaths and $50 \%$ of the world's disaster-related economic losses (ADRC 2016). Of these, floods consisted of $31 \%$ of the total number of disasters, followed by $28 \%$ for cyclones and typhoons. Therefore, hydrometeorological-related disasters are seen as the most prominent in Asia (Shaw 2006).

Being considerably susceptible to climate change, Vietnam was ranked the eighth among 10 countries in the world most harshly influenced by extreme weather events in the last two decades (Kreft et al. 2016; Nguyen Duc et al. 2019), and was also listed as one of five countries with the highest population proportion exposed to riverflood risks worldwide (Luo et al. 2015). Over the past 20 years, natural hazards and disasters have resulted in 650 deaths, affected 340,000 ha of paddy fields, and destroyed 36000 houses on average each year. The country has lost 1 to $1.5 \%$ of its annual gross domestic product (GDP) in the aforementioned period due to natural hazards and disasters, 
and this significantly hinders the socioeconomic reorganization process (WB 2010).

Over an extended period, conventional approaches to flood control have strongly relied on engineering works such as building dams and reservoirs. These approaches, however, were sometimes incapable of preventing flooding and associated losses (Pilarczyk and Nuoi 2002; Musiake 2003). It might be argued that flood threats continue to lurk regardless of the governments' ongoing efforts toward improving engineering works (Sayers et al. 2015; Chen and Lin 2018). This fact also implies the importance of being prepared to deal proactively with unforeseen events instead of putting full faith in the structural works.

Shifting from a purely technical-oriented defense toward a more integrated flood risk management system has been recommended in various countries (Hartmann and Albrecht 2014). In Vietnam, the responsibility of local authorities and households in alleviating flood distress has been embedded into the national strategy for disaster prevention. It was further emphasized, especially after fateful disasters such as the 1999 historic flood in Thua Thien Hue Province, which flooded $90 \%$ of lowland areas in a week, and induced up to USD 120 million tangible losses (Tran and Shaw 2007).

Since the hierarchical structure of the administrative system reveals limitations in risk management, there is a transition underway to more resilient approaches such as bottom-up initiatives (Zevenbergen et al. 2008) and community-based systems (Aalst et al. 2008). In such approaches, precautions implemented by local actors such as local authorities and private households are highly encouraged (Duc et al. 2012; Chinh et al. 2016; Atreya et al. 2017; Luu et al. 2018). In Vietnam, for instance, Luu et al. (2018) suggested that since communes have a deeper understanding of their local conditions, empowering them in the planning and decision-making processes is necessary to improve the effectiveness of flood risk management activities. Duc et al. (2012), meanwhile, further underlined the crucial role of preventive measures at the household level in mitigating the adverse effects of natural hazardrelated disasters.

These aforementioned studies, however, merely looked at the preparedness of the local actors only at the time the survey was conducted, overlooking its progression over time. In addition, there are relatively few empirical studies, especially in central Vietnam, that consider how villagers perceive the changes in flood characteristics, how local authorities and private households have improved precautions over the long term, and how coping capacities differ among social groups. Furthermore, studies examining barrier differences in enhancing protective measures between rural and suburban areas are still rare despite compelling evidence of the link between their socioeconomic disparities and the implementation of precautions.

To fill this gap of knowledge, this study, therefore, aimed to examine the long-term changes in precautionary measures for flood risk mitigation by focusing specifically on: (1) the changes in flood characteristics under the influence of the dam systems and the attitude of floodplain residents toward implementing precautions; (2) the precautions taken by the commune authorities and their effectiveness in supporting flood victims; (3) the long-term improvement in precautions of private households and their efficacy in reducing flood risks; and (4) the differences in coping capacities and constraints of social groups in both rural and suburban areas.

These issues were examined by comparing the two major floods that occurred in 1999 and 2017 in Thua Thien Hue Province, central Vietnam. Since floodwater depth is considered one of the determining factors of the damage extent (Thieken et al. 2005), the comparable water level caused by these two floods is crucial to ensure achieving the objectives of this study. This study may be useful to identify social groups lagging in the struggle against floods and recognize shortcomings in the design and implementation of flood-related policies.

\section{Study Site and Methods}

Thua Thien Hue Province, located in the north-central coastal region of Vietnam, was selected as the target region of this study based on its geographical features and flood history. A survey of local authorities and private households and quantitative and qualitative methods were used to collect and analyze the data.

\subsection{Study Site}

With a $128 \mathrm{~km}$ long coastline and interlaced river systems, Thua Thien Hue Province has experienced many hydrometeorology-related hazards, such as floods and storms. It is considered among the most disaster-prone areas of Vietnam (Tran et al. 2008).

Flood-associated losses have trapped many households in the vicious circle of poverty. The 1999 flood was deeply implanted in the minds of many people as a fearful memory, which took hundreds of lives and caused economic losses estimated up to millions of dollars (Valeriano et al. 2009). Flood-related concerns appear to have been somewhat liberated since the construction of massive hydroelectric dams. However, these fears were again triggered by the 2017 major flood, which occurred after storm No. 12 named Damrey with wind speeds up to $135 \mathrm{~km}$ per hour. This was the most powerful storm impacting Vietnam since 
2001 (UNDP 2018). Hydropower dams in Thua Thien Hue Province, under the influence of heavy rain due to the circulation of storm, had to release water, and thus caused widespread flooding in the downstream area. Although this led to a comparable floodwater depth, the damage was much lower than in the 1999 flood (Fig. 1). This outcome may be due to various factors, but highly likely includes the improvement in precautions.

The villages Trieu Son Nam and Bao Vinh in Huong Vinh Commune, Huong Tra District were selected for the survey (Fig. 2). The population of these villages was 1925 and 2032, respectively, corresponding to 402 and 515 households. Although drawn from the same commune, the first village represents rural characteristics with more than half of households involved in agriculture, while the second village possesses suburban features where retail and handicrafts are more dominant.

Both villages are located near the intersection of the Huong and Bo Rivers where they merge before emptying into the sea, which causes the currents to be more powerful and dangerous during floods. This terrain, combined with its low-lying topography, makes these villages more susceptible to flood-related hazards. In reality, the communities in this area have suffered heavy losses due to floods, especially in 1999. However, annual reports affirmed a favorable indication that flood-related damages had decreased despite severe floods similar to the 1999 event occurring on occasion. This implies that greater attention was given to flood risk management in this locality.

This site, therefore, was selected to explore the factors contributing to such achievement. Along with the comparison of rural and suburban villages, which have similar administrative systems but different socioeconomic characteristics, an indication of the limitations of social groups in coping with floods and their actual barriers is presented.

\subsection{Methods}

A pilot survey was performed to search for an appropriate study site before conducting the official survey in April and October 2018. The data were gathered from both local authorities and private households.

We obtained data on local socioeconomic characteristics and flood trends from the commune authorities. Flood prevention activities were also explored through direct interviews of those responsible for flood and storm control. These activities were further discussed with the village leaders since they are considered an essential link in the implementation process.

By using the face-to-face interview method, the crosssectional data of 120 households, divided equally between the two selected villages, were collected. To facilitate the survey, a semistructured questionnaire was developed after a thorough process of document review in combination with the consultation of specialists who are well-versed in both floods and village life. From the household lists provided by the village leaders, homeowners who met the following requirements were randomly selected for an interview: over 30 years old; experience of both the 1999 and 2017 floods; and direct involvement in the preparation of the flood defenses.

The interviews usually began with information regarding household demographic characteristics, followed by participants' perceptions of changes in flood risks, the potential causes for these changes, and their attitude toward precautions. As the beneficiaries, interviewees were then
Fig. 1 Flood peaks and tangible damages in Thua Thien Hue Province. $* 1$ USD $\approx 23,184$ VND. **Phu Oc is a hydrological station located in Huong Tra District. Source: People's Committee of Thua Thien Hue Province

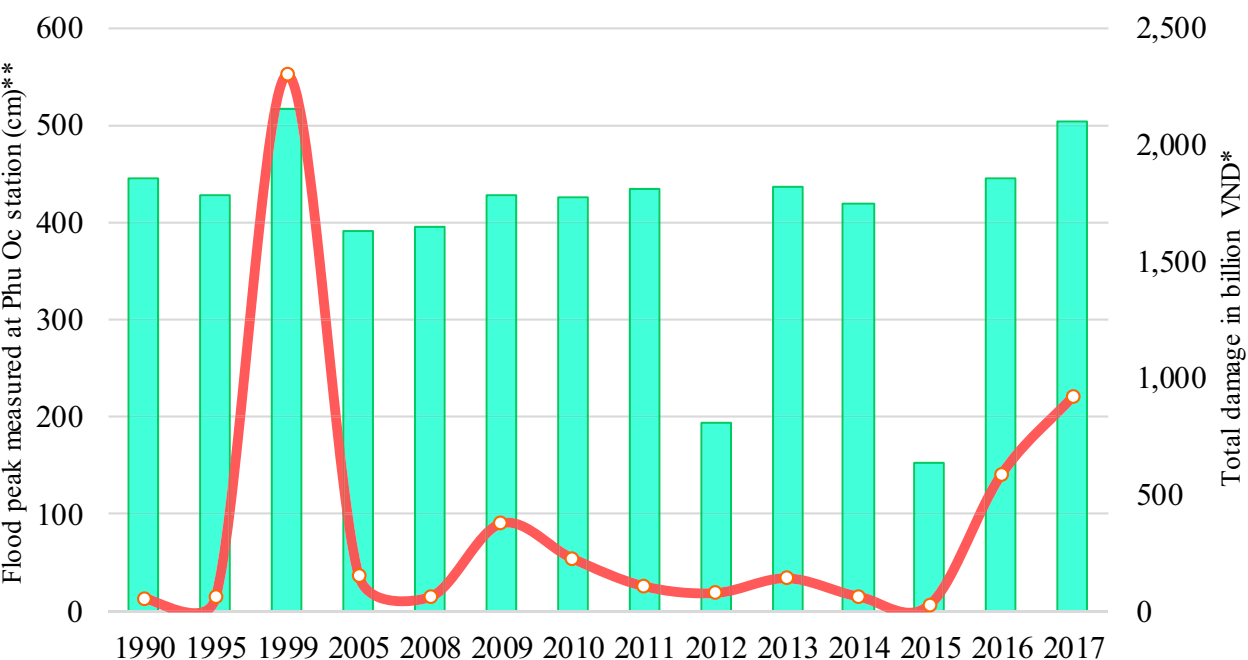

19901995199920052008200920102011201220132014201520162017

$\square$ Flood peak $\quad$ Total damage 


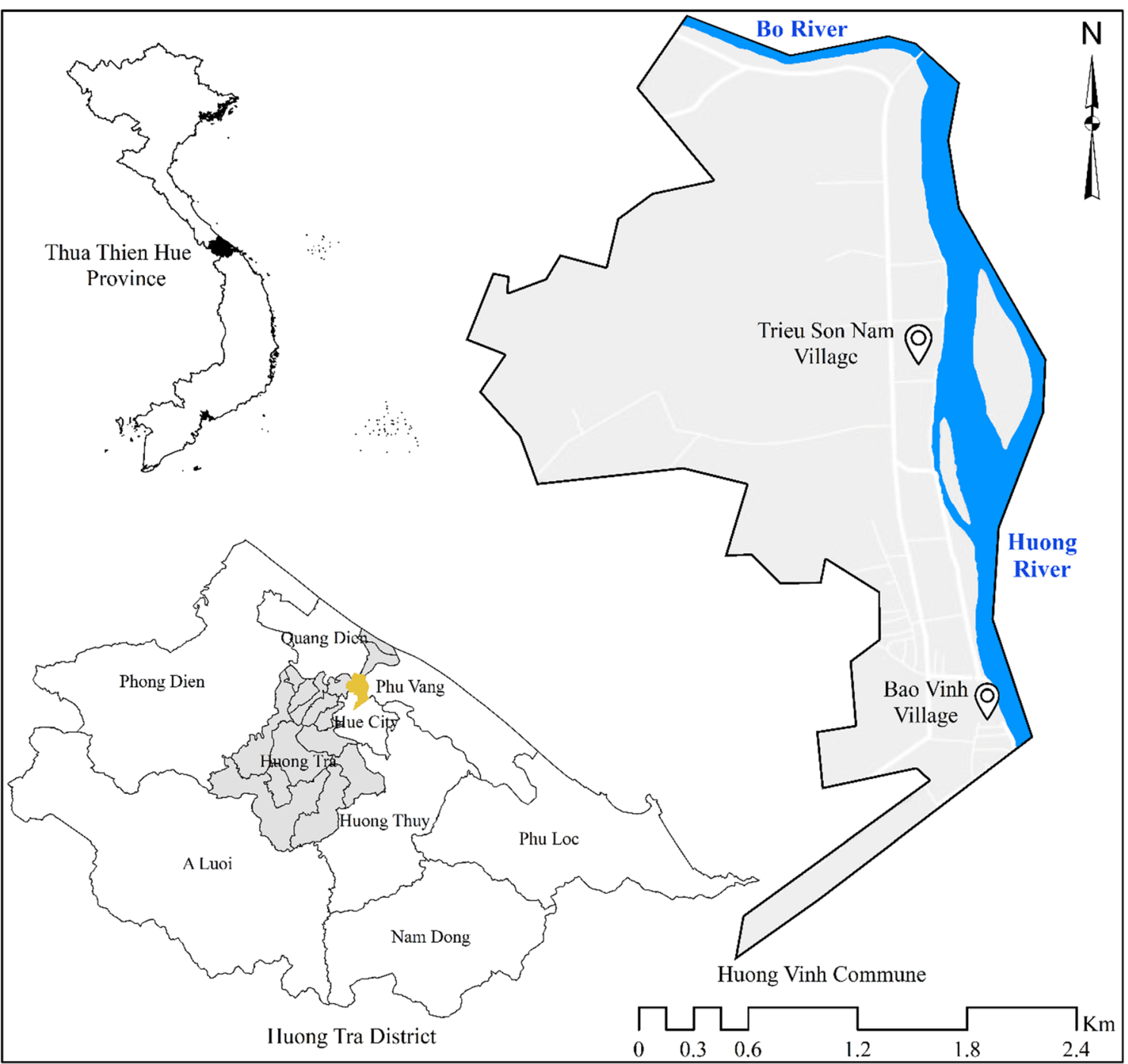

Fig. 2 Map of the study site

encouraged to express their views on the reliability of local authority actions, along with explanations for their assessment. Finally, key information on the preparation and damages of both floods was requested to understand the improvements in precautions and their damage-reducing effects.

This study adopted both quantitative comparative and qualitative descriptive approaches. The quantitative data were processed to observe the trends and cohesion between variables, while the qualitative information was used to further interpret the implications.

We first examined residents' perceptions of the changes in flood risks, potential reasons for these changes, and their protection behavior. In addition, preventive activities operated by local authorities and their reliability were revealed through practical experiences of the local people. We then focused on analyzing household measures and their effectiveness in reducing risks. In this study, the 1999 historical flood was seen as a powerful catalyst to drive households toward creating better defenses. Therefore, we expected significant positive differences in households' preparation and flood-related damages. Further to this, the indoor flood level between the two events was compared. From this, we expected lower levels of flooding as a direct result of upgrading structural measures.

Cross-tabulation analysis was chosen to explore the association between household characteristics and improvement in precautions. Popular protective measures were considered as dependent variables. Meanwhile, based on the literature review, income level, housing location, and external reliant psychology were included as explanatory variables. Higher-income households were reported to be better prepared for natural hazards (Hosseini et al. 2013; Ashenefe et al. 2017). Living in higher risk areas was found to be positively associated with households' preparedness (Hoffmann and Muttarak 2017; Wu 
et al. 2018). Reliance on external support was reported to be negatively correlated with protective responses (Grothmann and Reusswig 2006; Chen et al. 2019). In this study, household income was ranked by referring to the 2016-2020 living standard (Vietnamese Government 2015) and the 2017 report on the average income (GSO 2017). Households with a per capita income of less than VND 1.3 million were considered to be in the low economic class, while those that exceeded VND 4.5 million were regarded as a higher socioeconomic class. Location was classified based on distance to the riverbank with a delimitation of around $30 \mathrm{~m}$. Households' external reliant psychology was decided by taking into account their belief in emergency support. Those who had high trust in the availability of external support in urgent cases were viewed as the external reliant group.

We also included some additional variables, such as the number of laborers, occupational stability, dependency ratio, and living with disabilities, to gain insight into the constraints of the households. To better reflect household resources, the occupation that contributed the most to a household's income was chosen rather than that of interviewees and was further classified based on its stability. Dependency ratio was calculated as a fraction of the total number of individuals who are not working divided by those who contribute to the income, regardless of their age. A higher value of this ratio implies a greater strain imposed on the household. Similarly, living with disabled family members was also added as a barrier to the implementation of protective measures.

\section{Results and Discussion}

In this section, the data obtained through household interviews are analyzed in the following order: sociodemographic characteristics of the surveyed households; changes in flood characteristics and household protective behavior; precautions of local authorities; changes in household precautions and damage-reducing effectiveness; and household characteristics and improvement of preventive measures.

\subsection{Sociodemographic Characteristics of the Surveyed Households}

Male household heads accounted for more than two-thirds of the samples. The majority of respondents were middleaged $(43.3 \%)$ and older $(41.7 \%)$. Farming was the most dominant occupation in the rural village, while retails and handicrafts were the most well known in the suburban area. Only around $40 \%$ of the study population had stable occupations, while up to one-third of families relied largely on precarious livelihoods. More than half of households were classified as middle level, while around a quarter were defined as poor. With regard to human resources, $43.3 \%$ of households in the suburban area had more than two laborers, a little higher than that in the rural area. Semipermanent houses were the most typical, accounting for over $60 \%$ of the total, and only one-third had been upgraded to permanent housing, while $6.7 \%$ remained temporary. Moreover, $27.5 \%$ of those dwellings were erected adjacent to the riverbank. Regarding the dependency ratio, more than half of the households had more laborers than dependents. Additionally, a quarter of those interviewed were living with elderly or disabled family members.

\subsection{Changes in Flood Characteristics and Household Protective Behavior}

The extent of damages depends on how people prepare for encounters with potential risks (CMCC 2018). Their preparation is driven by the comprehension of changes in flood trends and risks (Reynaud et al. 2013). Therefore, the interviewees were asked to express their views on the changing nature of floods (Fig. 3).

Most respondents asserted that floods are currently progressing in a favorable direction. In particular, less flooding was indicated by $59.2 \%$ of the informants, while only $3.3 \%$ signified the opposite. Nearly $67 \%$ of the informants confirmed less severity and faster drainage of floods, while its delayed appearance was clarified by almost $62 \%$. In contrast, the majority of the interviewees (75.8\%) complained about the increasing irregularity and unpredictability of floods. These changes were attributed to the increasing prevalence of dams. Currently, some 62 reservoirs for both irrigation and hydropower are being operated in the province. Alongside visible contributions, these massive structural works conceal many unanticipated dangers (Blöschl et al. 2015).

This fact inspired us to further explore residents' attitudes toward implementing precautions. Maintaining similar preparations to previously was the response of onethird of the interviewees. Meanwhile, more than half $(54.2 \%)$ suspected the stability of these structural solutions and were concerned about abrupt calamities. Hence, they believed that more attention should be paid toward precautions. In contrast, a small minority $(12.5 \%)$ underestimated precautions, believing they were safeguarded by massive dams. This subjectivity may stem from the fact that low-probability natural hazard-related incidents are often misjudged systematically (Faure 2007).

Although the government has made great efforts to erect structural works, they are just one part of the integrated flood risk management strategy. It should be recognized 
Fig. 3 Perception of changes $(\%)$ in flood characteristics $(\mathrm{N}=$ 120). Source Household interviews 2018

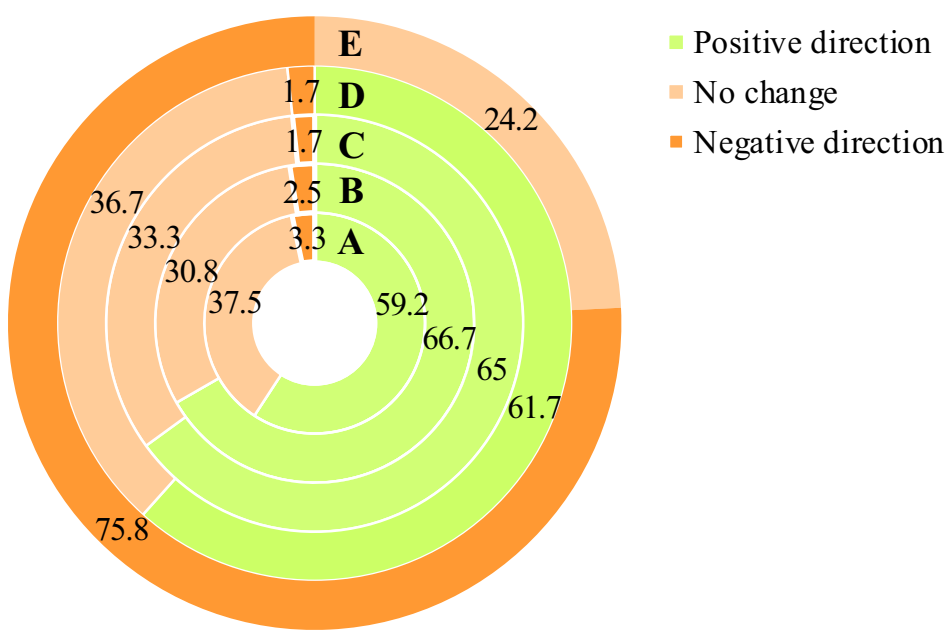

A- Frequency B- Magnitude C-Duration D- Striking time E-Predictability that flood damages can never be wholly mitigated by relying solely on these public defenses (Hoffmann and Muttarak 2017). Strengthening the role of local actors, therefore, is critical to compensate for the limitations of the engineering approach.

\subsection{Precautions of Local Authorities}

Two months before the flood season, the flood prevention committees are reorganized at both commune and village levels. These are permanent groups of nearly 20 members from various political, social, and economic organizations. They are established to support local communities to effectively work against floods. Support from these committees primarily relies on local resources and can be split into structured and non-structured forms. Structural measures aim to improve the quality of roads, strengthen riverbanks, and most importantly, prepare shelters for emergency evacuation. Schools and healthcare centers, which have already been solidified, are used as refuges during severe inundation. Meanwhile, non-structural measures include providing early warnings, emergency necessities, and means of escape. Warnings are spread through two main channels: a loudspeaker system operated by the local authority, and portable-speakers run by village teams. At the beginning stage of floods, villages are responsible for other supports, such as food and early evacuation, but due to a lack of resources, this applies only to some households living on perilous terrain. These supports are intensified by utilizing the commune's stockpile whenever extreme floods occur.

Nevertheless, it is neglectful to ignore the impressions of the population who directly benefited. Therefore, interviewees were asked to express their opinions on these supports (Fig. 4). Of the study population, nearly three- quarters appreciated the improvements to the early warning system, a quarter were doubtful, and only $2.5 \%$ were flatly unsatisfied. Conversely, $76.7 \%, 82.5 \%$, and $69.2 \%$ of the respondents were dissatisfied with the support of basic necessities, emergency evacuation, and post-flood recovery, respectively. Besides the above-mentioned immediate supports, the current transportation infrastructure was much improved after several upgrades, which facilitated the flood coping process. The riverbanks, however, have not yet been fortified, leaving riverside households more susceptible during floods.

The beneficiaries were also required to disclose the main reasons governing their estimations. Absence of the village communicators was reflected by nearly $22 \%$ of those surveyed, while others disparaged the local broadcast system quality. Usually, the village board directly broadcasts warnings to every alley, and this process is repeated several times. However, this may be futile if residents are absent from their homes during the transmission. Regarding the loudspeaker, even with a wider range, this system is ineffective for those living far from radio stations, especially in tumultuous weather conditions. Likewise, the broadcast may be interrupted or deactivated due to power outages during heavy floods, which was mentioned by nearly $16 \%$ of the samples. The support of necessities was underrated due to negligible quantity $(86.7 \%)$ or late distribution $(75.8 \%)$. Food reserves were only deployed at the commune but disregarded within the villages due to financial constraints. Normally, relief goods were only distributed to victims after the floods had begun to recede. This, in addition to the small supported amount, led to the ineffectiveness of this effort.

Perception of failure in supporting emergency evacuation was due to the sparsity of shelters $(78.3 \%)$ and suspicion about the authority's capacity (91.7\%). Preparing 
Fig. 4 Perception of the public support reliability $(\mathrm{N}=120)$. Source Household interviews 2018

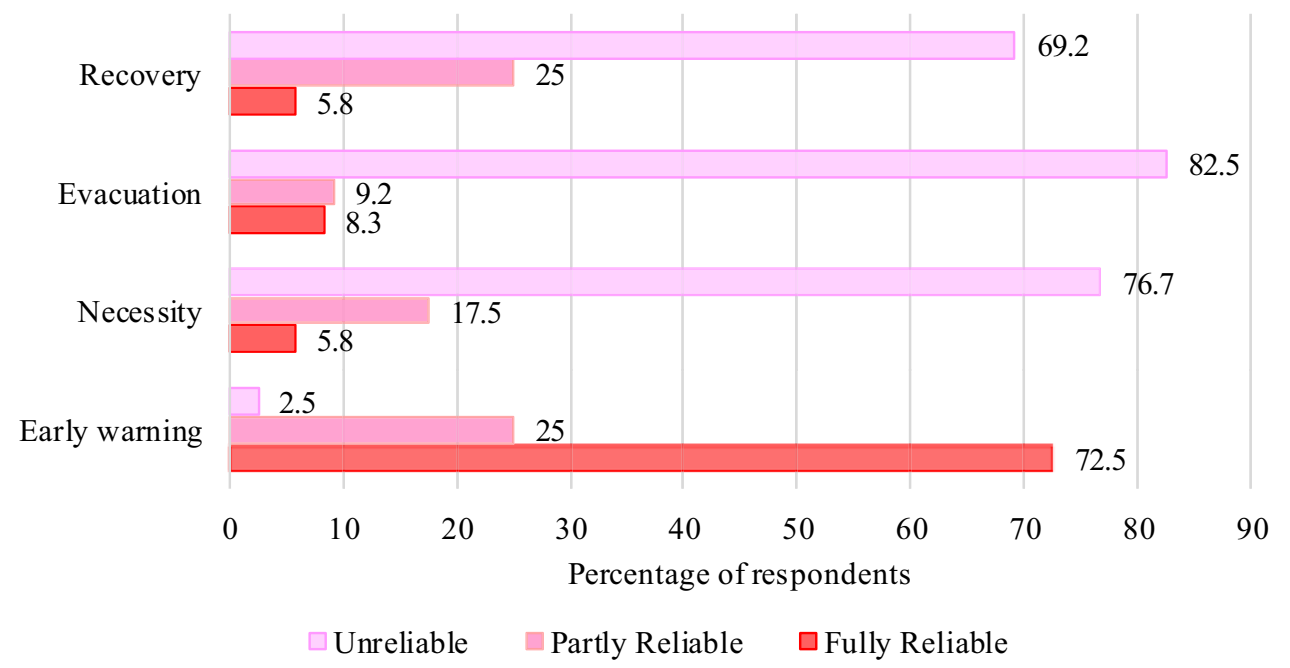

emergency shelters and transport is obligatory to assure speed, timeliness, and safety in an evacuation. Recognizing these requirements, public infrastructures were reinforced by local authorities. These infrastructures, however, are scattered and far from most residential clusters. Approaching these shelters, therefore, becomes extremely arduous and perilous due to high floodwater level and swift-flowing currents. Most respondents were also skeptical of the authorities' ability to mobilize sufficient manpower and necessary facilities for evacuating an enormous number of households simultaneously.

Besides the above precautions, preparation for postflood recovery is also important because neutralizing all flood impacts is impossible. However, once again the respondents lacked faith in the local authorities because of their limited financial resources (90\%) and delays in implementation $(55.8 \%)$. In fact, post-disaster supports were usually distributed to only a few households that had suffered major losses and took a long time to implement. In addition, the compensation amount was insubstantial compared to the losses and thus less meaningful for flood victims. It is undeniable that almost all damages suffered by residents tend to be neglected after disasters.

\subsection{Changes in Household Precautions and Damage-Reducing Effectiveness}

This section focuses on analyzing the improvement of preventive measures at the household level and their effectiveness in reducing damage between the 1999 and 2017 floods.

\subsubsection{Changes in Household Precautions}

Most residents were aware of potential threats despite the protection of the engineering works and they distrusted the support measures offered by local authorities. These findings raise the question of how floodplain inhabitants have improved preventive measures and how effective those improvements are during floods. To clarify these matters, the main measures implemented by households in the 1999 and 2017 floods were recalled (Table 1).

Obviously, all measures have vastly improved after nearly 20 years. While almost all measures were implemented by less than $50 \%$ of the respondents in 1999 , they were mostly greater than $70 \%$ in 2017 ( $p<0.01)$. Households tend to solidify housing by using waterproof materials instead of fragile materials such as bamboo and thatch. Raising ground was also a widespread solution to reduce indoor flooding. Both of these solutions were deployed by over $90 \%$ of those surveyed in 2017, much higher than those in 1999 (below 30\%). Additionally, the proportion of houses with additional floors doubled from 35.8 to $74.2 \%$.

Similarly, the official warning was disseminated to almost all residents in 2017 (97.5\%), as opposed to 1999 (17.5\%). This may be principally due to the authorities' efforts, but could also be achieved through proactive seeking of warning information by households. Storing sufficient food, though a simple task, is essential to uplift human endurance, especially for abnormally long-lasting floods. In 1999, nearly $60 \%$ of households stored food for at least three days. Meanwhile, the remainder believed that foodstuff could be easily replenished from peddlers when the floods retreated. However, this could be a dangerous misconception that could turn into unpredictable risk, since the 1999 flood lasted for a week, which led many households into food scarcity. In 2017 , therefore, up to $95.8 \%$ of households accumulated enough food for a normal-length flood. Furthermore, up to $92.5 \%$ of households prepared alternative energy sources such as gas stoves or 
Table 1 Main measures implemented by households before 1999 and 2017 floods $(\mathrm{N}=120)$. Source: Household interviews 2018

\begin{tabular}{|c|c|c|c|c|c|}
\hline \multirow[t]{2}{*}{ Measures } & \multicolumn{2}{|c|}{1999 Flood } & \multicolumn{2}{|c|}{2017 Flood } & \multirow[t]{2}{*}{$p$-Value ${ }^{\mathrm{a}}$} \\
\hline & $\mathrm{n}$ & $\%$ & $\mathrm{n}$ & $\%$ & \\
\hline Housing reinforcement & 27 & 22.5 & 113 & 94.2 & $<0.01$ \\
\hline Raising ground & 25 & 20.8 & 111 & 92.5 & $<0.01$ \\
\hline Install sub-floors & 43 & 35.8 & 89 & 74.2 & $<0.01$ \\
\hline Access to official warnings & 21 & 17.5 & 117 & 97.5 & $<0.01$ \\
\hline Store food for at least three days & 71 & 59.2 & 115 & 95.8 & $<0.01$ \\
\hline Effective plan to compensate for energy loss & 56 & 46.7 & 111 & 92.5 & $<0.01$ \\
\hline Effective plan to protect valuable assets & 27 & 22.5 & 86 & 71.7 & $<0.01$ \\
\hline Specific plan for emergency evacuation & 27 & 22.5 & 68 & 56.7 & $<0.01$ \\
\hline
\end{tabular}

${ }^{a}$ McNemar's Chi-square test by binominal distribution

rechargeable lamps in case of power interruption, compared to just $46.7 \%$ in 1999.

In economic terms, floods are one of the costliest natural hazards and disasters (Saeed et al. 2018). In fact, $77.5 \%$ of households lost most valuable assets in the 1999 flood. Asset protection, however, was much better implemented by 2017 as most households $(71.7 \%)$ successfully preserved their assets after the flood. Most of the respondents actively prepared more items such as bricks, wooden planks to lift up movables, or suspension systems to fasten water-sensitive objects to the ceiling. Highly mobile assets, such as motorbikes or agricultural machines, were shifted to safe places whenever imminent flooding was announced.

Drawing up a detailed evacuation plan is an effective way to minimize both human casualties and property damage. While most households were passive in the evacuation in 1999, this was greatly improved in 2017 . The proportion of households who prepared an evacuation plan doubled from 22.5 to $56.7 \%$. Frail members are often evacuated before flooding, especially those living in hazardous areas, while others stay to protect belongings from thieves. Although currently less useful for livelihoods, some households still retain boats as a transportation means during floods. There was one boat for every five households, which was often used as common property in cases of emergency. However, this was mostly in the rural area and rare in the suburb. This was due to narrow living spaces and the lack of connection between suburban livelihoods. Those in better-off households simply moved to the second solid floor. Others planned to reach to and shelter in adjacent solid houses. Although dangerous, this may be feasible due to the dense housing. Although there has been a significant improvement, $43.3 \%$ of the households were still inactive in outlining evacuation plans, and mainly looked for external help.

\subsubsection{Damage-Reducing Effectiveness}

We first compared the actual indoor flood level, which is different from the land-surface flood depth, to understand the effectiveness of raising the ground (Fig. 5). The 2017 indoor flood depth $\left(\right.$ mean $^{2017}=0.776 \mathrm{~m}$; median $^{2017}=0.7$ $\mathrm{m})$ was much lower than that in $1999\left(\right.$ mean $^{1999}=1.952 \mathrm{~m}$; median $^{1999}=2.0 \mathrm{~m}$ ). The interquartile ranges further indicate that $75 \%$ of shelters were flooded to at least $1.7 \mathrm{~m}$ in 1999 , while $75 \%$ of those were submerged below $1.2 \mathrm{~m}$ in 2017. This result is further affirmed by the equivalent flood peaks of the events in 1999 (518 cm) and 2017 (505 cm) (Fig. 1). Such comparison demonstrates the effectiveness of raising housing ground for reducing the indoor flood depth.

Fewer damages were anticipated due to lower indoor floods experienced by most households in 2017. Due to the long interval between the two events, damages were recorded by category instead of the currency unit. Moreover, certain types of damage relating to injuries, food shortages, or evacuation may be impossible to convert into monetary units.

Table 2 shows that damages in 2017 were significantly lower than those in 1999. The percentage of people injured in 2017 (1.7\%) was much lower than in 1999 (16.7\%). People were normally wounded during evacuation due to the lack of supportive equipment. Therefore, the decline in the evacuation rate from 58.3 in 1999 to $8.3 \%$ in 2017 may have contributed to reducing the injured rate. Regarding physical losses, $65.9 \%$ of houses were damaged to varying degrees in 1999, but this dropped sharply to just $15 \%$ in 2017. This improvement may be partly due to a less severe flooding in 2017 but more likely stems from households' efforts to upgrade housing. Over $98 \%$ of the households reported that most of their assets were submerged by floodwaters in 1999. However, this rate dropped noticeably 


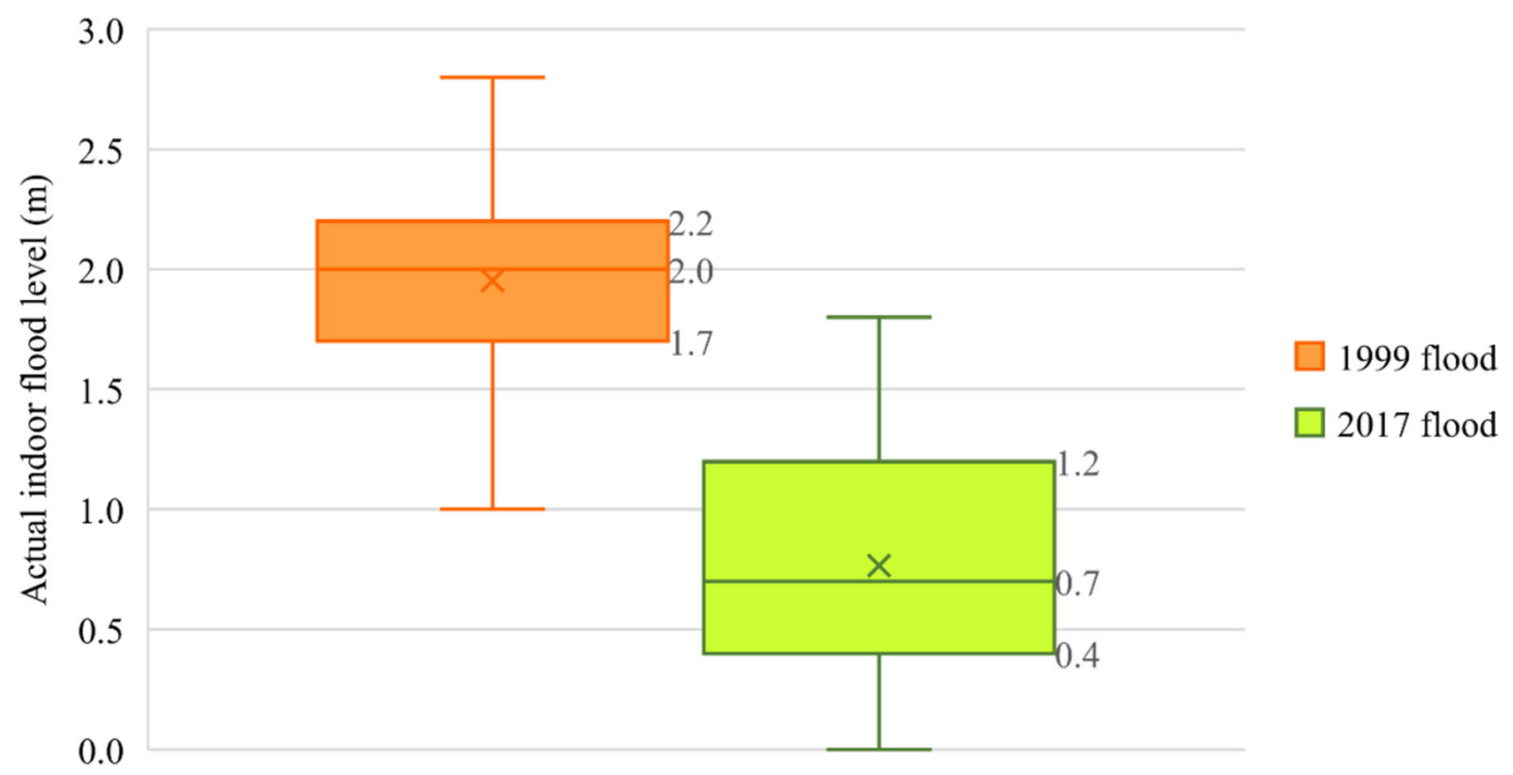

Fig. 5 Comparison of actual indoor flood levels in 1999 and 2017. Source Household interviews 2018

Table 2 Percentage of households affected by the 1999 and 2017 floods $(\mathrm{N}=120)$. Source: Household interviews 2018

\begin{tabular}{|c|c|c|c|c|c|}
\hline \multirow[t]{2}{*}{ Damages } & \multicolumn{2}{|c|}{1999 Flood } & \multicolumn{2}{|c|}{2017 Flood } & \multirow[t]{2}{*}{$p$-Value ${ }^{\mathrm{a}}$} \\
\hline & $\mathrm{n}$ & $\%$ & $\mathrm{n}$ & $\%$ & \\
\hline Members injured & 20 & 16.7 & 2 & 1.7 & $<0.01$ \\
\hline House fully collapsed & 8 & 6.7 & 1 & 0.8 & $<0.05$ \\
\hline House partly collapsed & 71 & 59.2 & 17 & 14.2 & $<0.01$ \\
\hline Property damaged & 118 & 98.3 & 40 & 33.3 & $<0.01$ \\
\hline Lack of food & 92 & 76.7 & 4 & 3.3 & $<0.01$ \\
\hline Evacuated & 70 & 58.3 & 10 & 8.3 & $<0.01$ \\
\hline
\end{tabular}

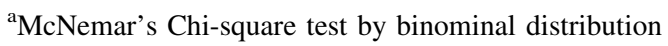

to $33.3 \%$ in 2017 . Food security was also significantly improved, with only $3.3 \%$ of households suffering from food shortages, compared with $76.7 \%$ in 1999 . It can be assumed that households' efforts in improving precautions contributed significantly to reducing indoor flooding, thereby mitigating the associated damages.

\subsection{Household Characteristics and Improvement of Preventive Measures}

Improving precautions has shown positive effects on flood risk mitigation, as found by Kreibich et al. (2011), Poussin et al. (2015), and Atreya et al. (2017). Who is plodding in the struggle against floods? And what factors are hindering them? These matters still need to be investigated for identifying the characteristics of the least improved groups.
The overall sample, therefore, was split into rural and suburban groups based on their socioeconomic disparity. The popular actions taken by the residents were also divided into different levels and regarded as dependent variables (Table 3). As mentioned in the method section, three characteristics of households, including income level, housing location, and external reliant psychology, are used as predictors. Some other demographic characteristics of households are also used to further explain their constraints.

\subsubsection{Characteristics Associated with Improvements in the Rural Village}

Table 4 shows that the improvement in precautionary measures in the rural village is distinctly divided by income levels. Income creates significant differences in house reinforcement $(p=0.00)$, ground raised $(p=0.00)$, and subfloor setting $(p=0.00)$. Further inspection of the Cramer's $\mathrm{V}$ coefficients suggests that the strength of these associations is moderately strong $(V=0.562 ; V=0.546 ; V=$ 0.593). Accordingly, the lower-income group appears lower with regard to upgrading housing. This result is consistent with the finding of Kreibich et al. (2011), which underscores the crucial role of financial-related factors in implementing structural measures. Furthermore, lower-income earners are also less likely to improve non-structural measures, including accessing warnings, storing food, and planning evacuation. Cramer's $\mathrm{V}$ values indicate a strong cohesion between these relationships $(V=0.414 ; V=$ $0.610 ; V=0.588)$. 
Table 3 Classification of improvement level

\begin{tabular}{|c|c|c|}
\hline Measures & Improvement level & Descriptions \\
\hline \multirow[t]{2}{*}{ Housing reinforcement } & Slightly & Minor or temporary reinforcement \\
\hline & Significantly & Major or permanent reinforcement \\
\hline \multirow[t]{2}{*}{ Raising ground } & Slightly & Raising the ground less than $1 \mathrm{~m}$ \\
\hline & Significantly & Raising the ground by at least $1 \mathrm{~m}$ \\
\hline \multirow[t]{3}{*}{ Setting sub-floors } & Unimproved & Not installing sub-floors; not reinforcing existing floors \\
\hline & Slightly & Installing new temporary floors; reinforcing existing floors \\
\hline & Significantly & Installing new solid floors; maintaining existing solid floors \\
\hline \multirow[t]{2}{*}{ Accessing warnings } & Slightly & Receiving official warnings from a single source \\
\hline & Significantly & Receiving official warnings from multiple sources \\
\hline \multirow[t]{3}{*}{ Food storage } & Unimproved & Preparing food for three days \\
\hline & Slightly & Preparing food for around 5 days \\
\hline & Significantly & Preparing food for more than 5 days \\
\hline \multirow[t]{2}{*}{ Evacuation planning } & Unimproved & Not knowing any shelter or way to access safely \\
\hline & Improved & Knowing shelters and ways to access safely \\
\hline
\end{tabular}

It is easy to comprehend the connection between implementing costly measures and households in the lower-income bracket since it is closely related to their financial capacity. However, access to official warnings is also restrained by income, while it should be equally delivered to all residents as a free public service. Nearly half $(44 \%)$ of the population who were characterized by meager income generally receive official warnings from a single provider rather than in a multidimensional manner. The wide rural residential area associated with inadequate equipment may partly result in the low coverage capacity of the warning transmission. Additionally, this may be ineffective if a household's members are at work and thus absent from their home when warnings are being announced. These hypothetical situations may apply to the low-income group, who are regularly away from home for livelihood. Missing warnings is, therefore, possible.

Besides indicating the links between low income and inferior improvement of measures, exploring the root causes of poverty is necessary if policy-related solutions are to be designed. We found that poverty in rural areas is strongly related to labor shortages $\left(\chi^{2}=15.27 ; p=0.00\right)$, high dependency ratio $\left(\chi^{2}=19.44 ; p=0.00\right)$, living with disabilities $\left(\chi^{2}=17.94 ; p=0.00\right)$, and precarious careers $\left(\chi^{2}=35.77 ; p=0.00\right)$. In this regard, sharing earnings that are already insufficient with more people, especially disabled members, may further restrict household budgets for investing in protective measures. This result, however, differs from previous findings that households with disabled or unhealthy members are more likely to participate in disaster preparation (Ablah et al. 2009; Eisenman et al. 2009). The healthier financial condition of residents in developed countries compared to those in developing countries is probably the reason for this difference.

In addition to finance, the improvement of precautions is also influenced by external reliant psychology, but to a lesser extent. Households with external reliant thinking appear to be less active in improvement measures. For example, $56.5 \%$ of households in such groups have made no improvements in setting sub-floors compared to just $21.6 \%$ of those in the non-reliant group $(p=0.01)$. In this regard, financial pressure should be seen as the primary cause since almost half $(47.8 \%)$ of the members in the external reliant group were those living in poverty. Others argued that it is unnecessary to erect sub-floors because they trust their neighbors' support in the case of severe floods. The links between this psychological trait and the implementation of the remaining measures, however, are statistically insignificant. Housing location, which is frequently discussed in studies related to preparedness, is entirely separate from rural households' ability to improve preventive measures $(p>0.05)$.

\subsubsection{Characteristics Associated with Improvements in the Suburban Village}

With disparities in socioeconomic conditions, exploring the suburban village promised to reveal other valuable links. The results are summarized in Table 5 .

The role of financial-related factors is further highlighted by their relationship with protective actions in the suburb. Similarly, fewer improvements in both structural and non-structural measures tended to be attached to the low-income group $(p<0.05)$. In this area, uncertain 


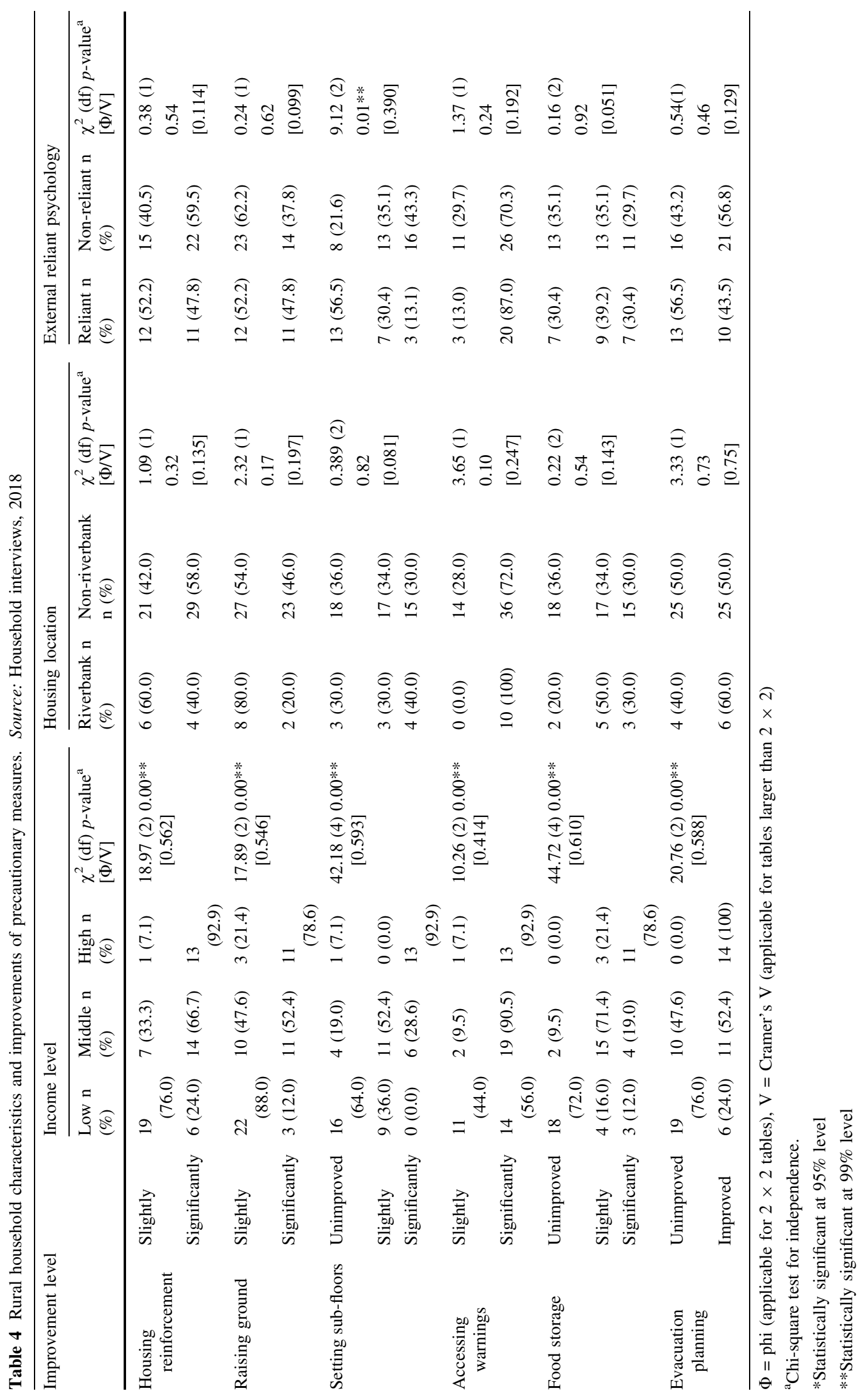




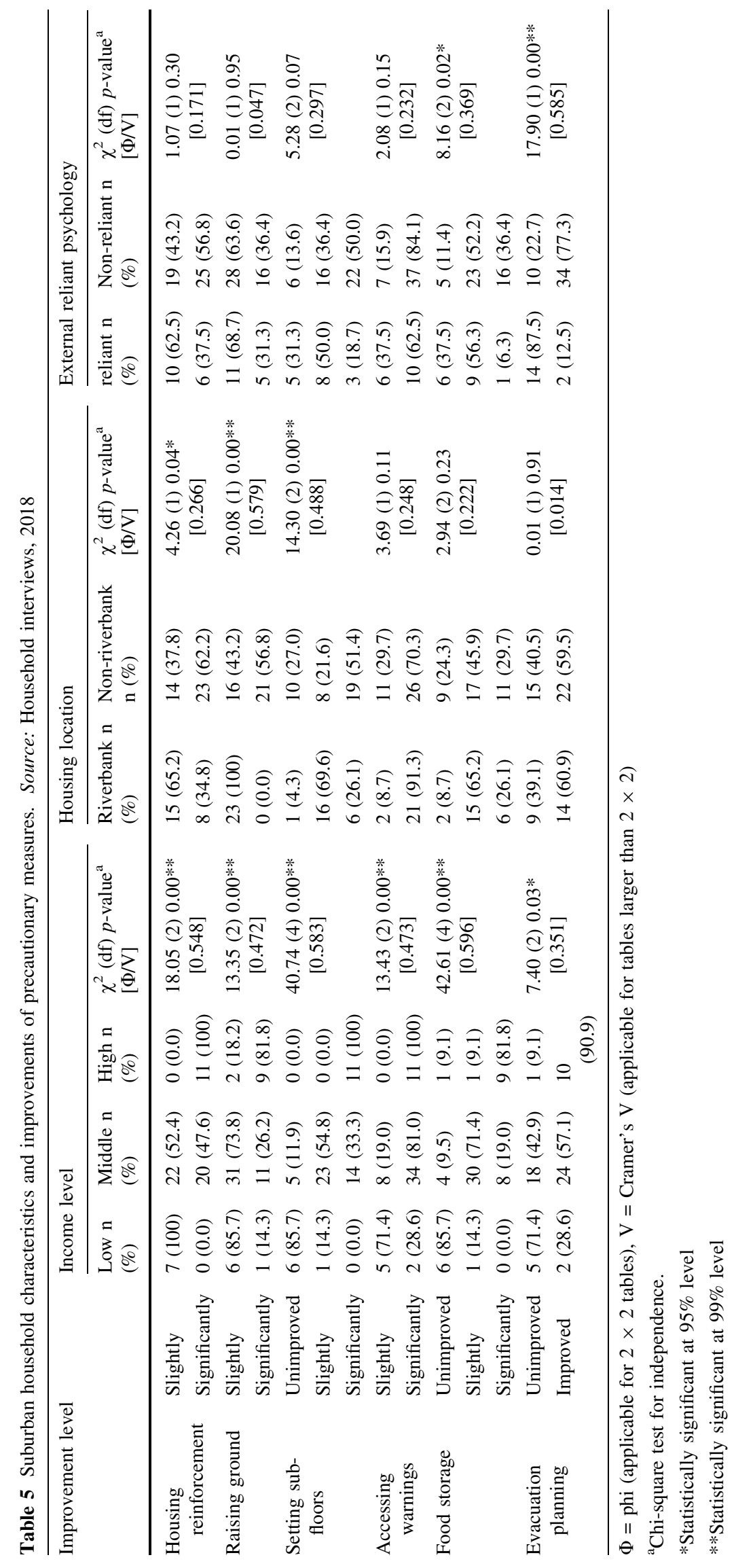


occupations $\left(\chi^{2}=29.19 ; p=0.00\right)$ and burdens from disabled members $\left(\chi^{2}=8.81 ; p=0.01\right)$ were found to be the causes of poverty.

Different from the rural village, housing location in the suburb had a significant effect on the improvement of structural measures. Families living adjacent to the riverbank appeared to be obstructed in reinforcing housing ( $p=$ $0.04)$, raising ground $(p=0.00)$, and setting sub-floors $(p=$ 0.00 ). Only $34.8 \%$ and $26.1 \%$ of households belonging to the riverbank group reached considerable levels in reinforcing housing and setting additional floors, respectively, while none achieved that level in raising ground. This group is mostly small-scale retailers with a middle-income level. For most, housing upgrades are probably not a big challenge after saving for a long time.

The field survey revealed that these poor improvements primarily stem from the provincial policy for restoration of the ancient city. Accordingly, households located in the planning area will be restricted from major upgrades so as to control the clearance compensation cost afterward. Although major reconstructions are still possible without an official license, those upgraded sections will not be compensated if the project is implemented. Furthermore, it should be stressed that, although initiated in the early 1990s, there has been no official decision made. This is the root cause constraining riverine households from upgrading structural measures.

Some households were prevented from raising the ground due to ancient housing architecture. Raising the ground excessively will make their habitable space significantly narrower. These families may also be more susceptible during the flood season since most have illegally encroached on the riverbed to broaden their residential space. The cramped housing has also prevented riverine households from purchasing boats for proactive evacuation. This is one of the reasons why nearly $40 \%$ have been unable to improve the evacuation plan. However, the relationship between housing location and making emergency evacuation plan is statistically insignificant $(p>$ $0.05)$.

The influence of psychological factors is again emphasized by its linkage with non-structural measures. People who have trust in various external supports appeared to pay less attention to food storage $(p=0.02)$ and evacuation planning $(p=0.00)$. The strength of these connections ranges from moderate to fairly strong $(V=0.369 ; \Phi=$ 0.585). As an example, $37.5 \%$ of households in the external reliant group stored food for only three days, while up to 87.5\% underestimated planning for an emergency evacuation. In contrast to the rural village, no connection between reliant thinking, poverty, and location was found. One possible explanation for the external reliant thinking of this type of residents relates to market functions in the area. Some residents believed that their shortcomings in preparation could easily be compensated by their neighbors, traders, as well as spontaneous services in the flood season. Living in the vicinity of the local market, where small retailers characteristically accumulate plenty of foodstuff for their daily business and there is a quite large number of boats passing during the flood season, may be the root of these passive ways of thinking.

\subsubsection{Comparison of Constraints between Rural and Suburban Villages}

Despite long-term efforts, some social groups remained less than impressive in improving preventive measures. There were similarities and differences in the constraints leading to these disquieting outcomes between rural and suburban villages. Poverty is an obvious obstruction in both areas since it is intricately linked to the improvement of all structural and non-structural measures. Labor shortages, high dependency ratio, living with disabilities, and precarious careers were the root causes of poverty in the study sites. This result strengthens the conclusion of Ahmad and Afzal (2020) that low financial status is the major obstacle of households to the implementation of risk reduction strategies. Other studies have also insisted that the poor are the most vulnerable to disasters and usually suffer greater damage than the wealthy (Fothergill and Peek 2004; Skoufias et al. 2011). This originates from their modest capacity to anticipate, respond, and recover from natural hazards (Wisner et al. 2003). The relationship between poverty and flooding is often seen as a vicious cycle. While floods cause or exacerbate poverty, poverty increases flood vulnerability (Dube et al. 2018; Kawasaki et al. 2020). Reducing poverty, therefore, should be a prerequisite in designing strategies related to flood risk mitigation.

Putting strong faith in external supports, besides implying strong cohesion within the community, should be considered a psychological barrier that leads to certain subjectivity. In particular, rural residents who had external reliant thinking were less focused on setting sub-floors while for those in the suburb it led to an underestimation of the importance of storing food and planning for evacuation. This result concurs with the findings of Chen et al. (Chen et al. 2019) and Grothmann and Reusswig (2006) that relying on external support leads households to disregard self-protective measures.

However, it is likely that the causes for this association between the rural and suburban areas are different. In the rural area, this may reflect a more abundant social capital compared to urban areas as found by Sørensen (2014). This tight connection in rural society allows residents to firmly trust in their neighbors to convey them to safe places such 
as permanent houses and a well-built church, as well as sharing a small amount of food in case of severe floods. It is also possible that the poor have their own strategy to mitigate flood risks since almost half of those in the external reliant group were classified as poor. Due to lack of financial capacity, the poor may prefer to invest in social capital to provide support in emergency cases. However, this reciprocal relationship can turn into external reliance since greater stocks of social capital were found to be associated with lower levels of risk perception and overestimation of self-capacity, which often undermine the intention to implement protective measures, making nonprotective responses such as wishful thinking, denial, or fatalism more likely (Babcicky and Seebauer 2017).

In the suburb, on the other hand, the residents' external reliant thinking may be driven by specific functions in the area. It is said that urban areas are composed of different functionally diversified units, and these are interrelated through complex systems (Wilson 1984), of which market/commercial functions are an essential part. As the center of urban functions, the local market provides diverse commodities and services, including essential ones in the case of emergency. This may induce inhabitants within these systems to believe that it is less necessary to undertake precautionary actions.

Further, the improvement of protective measures in the suburb was restricted by housing locations. Households living along the riverbank were less likely to improve structural measures. This unexpected outcome, besides being directly influenced by the susceptible location, concurrently resulted from the ancient house architectures and the ancient town's preserving policy. For ancient houses, raising the floor was generally limited to a certain extent to ensure sufficient space for daily activities. Besides this, the policy of preserving the ancient town significantly affected the implementation of structural measures. Under the regulation of this policy, major housing-related upgrading will not be compensated when undertaking the project. This placed riverside residents, therefore, in a dilemma between ensuring safety and maintaining livelihoods. Although initiated in the early 1990s, this project is currently pending approval so residents were unsure when it would be implemented and whether the project implementation will be better for them or not. In this regard, project implementation will probably release riverside households from the potential dangers of flooding by relocating them to more secure areas. However, resettlement to another area may be a serious threat to their livelihoods. As retailers, their families' livelihood heavily depends on the current location, which is close to both the local market and the main road. Therefore, a change to housing location will potentially disturb livelihoods. Most households, meanwhile, may not be ready to face this change due to a lack of occupational skills. From this result, we first reassert the previous findings of Tyas (2018) and Askman et al. (2018) on the binding between maintaining livelihoods and living in flood-prone areas. We also expose the inconsistency in designing and implementing development policies that may push residents into unfavorable and sometimes dangerous situations.

This overall comparison between rural and suburban villages underlines a more complex link between space, functions, and flood exposure in urban areas, as discussed by Sato (2006) and Ahmad and Simonovic (2013). One of the urban spatial characteristics diversified and segregated settlements and its functions, affects the long-term precautionary measures taken by individual households. It further emphasizes the additional complexity of coordinating projects in urban areas and exposes the adverse effects of incoherent policy mixture on improving protective measures of suburban residents, which could also be regarded as a product of the above-mentioned urban spatial characteristics.

\section{Concluding Remarks and Policy Implications}

Mitigating flooding threats remains a major challenge for the Vietnamese government despite interminable efforts to expand engineering works. That context requires an integrated management strategy by incorporating bottom-up approaches. The main aim of this study, therefore, was to examine the extent of long-term improvements to flood precautions taken by local authorities and private households between the two major floods of 1999 and 2017.

The findings first emphasize the increasing irregularity and unpredictability of floods, thus making it more difficult to anticipate through conventional approaches since the increasing popularity of the dam system in Thua Thien Hue Province. The majority of residents, therefore, doubted the efficacy of this top-down approach in reducing risks and suggested that more attention should be paid toward flood preparedness.

Several public measures were implemented to enhance the defenses of local inhabitants. However, except for the early warning systems being regarded as much more effective operations after nearly two decades, other measures relating to food reserves, emergency shelters, evacuation supports, and resources for post-flood recovery were still considered scant and distrusted by most residents. The inadequate investment in preventive measures due to limited financial resources and the authorities' delayed response to emergencies, as is often seen in developing countries, was one of the primary reasons for the inefficiency of the above-mentioned efforts. Household selfpreparation, therefore, became the decisive factor in flood 
risk protection. Nearly 20 years after the disastrous flood of 1999, most households paid greater attention to both structural and non-structural protective measures to actively deal with flood hazards. The damage caused by floods since has noticeably diminished. This confirms the central role of individual households in the bottom-up flood risk management strategy, especially in developing countries.

Some social groups, nonetheless, appear to be lagging behind in this struggle against nature, which was evidently expressed through their underperformance in the long-term improvement of precautionary measures. Poverty-related barriers were the root causes restraining the improvement of households in both rural and suburban villages. Hence, poverty eradication is a prerequisite to mitigating risks and should be integrated into flood risk management strategy as a foremost priority. Furthermore, households' external reliant psychology, though less common in the communities, also created subjective attitudes toward improving some types of personal precautions. While external reliant psychology in rural areas was attached to residents' abundant social capital, in the suburbs this was likely to be attributed to specific functions such as local markets. Breaking down this psychological barrier is essential to improve precautions further, but this should be done by thoroughly considering this difference between areas.

The riverine suburb in the study area was further identified as vulnerable based on their limitations in upgrading structural measures. This matter, apart from being affected by the precarious location itself, was strictly regulated by the policy for preserving and restoring the ancient landscape along the riverbank. Their vulnerability to floods, meanwhile, potentially can turn into livelihood vulnerability if the project was implemented. This, on the one hand, indicates the additional complexity of coordinating projects in urban areas, while on the other, requires a smoother blend of development policies to limit adverse implications.

Besides revealing the connections between poverty, external reliant psychology, and potential flood risk susceptibility, this study, by comparing two villages in terms of vulnerability, emphasized the importance of spacefunction links in the suburban area and the contradictions of different policy initiatives, such as landscape rehabilitation, disaster prevention, and livelihood maintenance. Therefore, besides considering social and geography differences, supportive solutions targeting vulnerable groups should be combined with effective public measures and a coherent mix of policies for further improvements.

Acknowledgements This study was financially supported by the Vietnamese government and Okayama University, Japan. Besides, we would like to express our gratitude to the People's Committee of
Huong Vinh Commune, village leaders (Mr. Sáu and Mr. Thái), and the communities in Bao Vinh and Trieu Son Nam villages for their support during the survey.

Open Access This article is licensed under a Creative Commons Attribution 4.0 International License, which permits use, sharing, adaptation, distribution and reproduction in any medium or format, as long as you give appropriate credit to the original author(s) and the source, provide a link to the Creative Commons licence, and indicate if changes were made. The images or other third party material in this article are included in the article's Creative Commons licence, unless indicated otherwise in a credit line to the material. If material is not included in the article's Creative Commons licence and your intended use is not permitted by statutory regulation or exceeds the permitted use, you will need to obtain permission directly from the copyright holder. To view a copy of this licence, visit http://creativecommons. org/licenses/by/4.0/.

\section{References}

Aalst, M.K.V., T. Cannon, and I. Burton. 2008. Community level adaptation to climate change: The potential role of participatory community risk assessment. Global Environmental Change 18: $165-179$.

Ablah, E., K. Konda, and C.L. Kelley. 2009. Factors predicting individual emergency preparedness: A multi-state analysis of 2006 BRFSS data. Biosecurity and Bioterrorism: Biodefense Strategy, Practice, and Science 7(3): 317-330.

ADB (Asian Development Bank). 2013. The rise of natural disasters in Asia and the Pacific: Learning from ADB's experience. Metro Manila, Philippines: ADB.

ADRC (Asian Disaster Reduction Center). 2016. Natural disaster data book 2015: An analytical overview. https://www.adrc.asia/ publications/databook/ORG/databook_2015/pdf/Data Book2015_e.pdf. Accessed 13 Apr 2020.

Ahmad, D., and M. Afzal. 2020. Flood hazards and factors influencing household flood perception and mitigation strategies in Pakistan. Environmental Science and Pollution Research 27: 15375-15387.

Ahmad, S.S., and S.P. Simonovic. 2013. Spatial and temporal analysis of urban flood risk assessment. Urban Water Journal 10(1): 26-49.

Ashenefe, B., M. Wubshet, and A. Shimeka. 2017. Household flood preparedness and associated factors in the flood-prone community of Dembia District, Amhara National Regional State, northwest Ethiopia. Risk Management and Healthcare Policy 10: 95-106.

Askman, J., O. Nilsson, and P. Becker. 2018. Why people live in flood-prone areas in Akuressa, Sri Lanka. International Journal of Disaster Risk Science 9(2): 143-156.

Atreya, A., J. Czajkowski, W. Botzen, G. Bustamante, K. Campbell, B. Collier, F. Ianni, and H. Kunreuther et al. 2017. Adoption of flood preparedness actions: A household level study in rural communities in Tabasco, Mexico. International Journal of Disaster Risk Reduction 24: 428-438.

Babcicky, P., and S. Seebauer. 2017. The two faces of social capital in private flood mitigation: Opposing effects on risk perception, self-efficacy and coping capacity. Journal of Risk Research 20(8): 1017-1037.

Blöschl, G., L. Gaál, J. Hall, A. Kiss, J. Komma, T. Nester, J. Parajka, and R.A.P. Perdigão et al. 2015. Increasing river floods: Fiction or reality?. Wiley Interdisciplinary Reviews: Water 2(4): $329-344$. 
Chen, Y., and P. Lin. 2018. The total risk analysis of large dams under flood hazards. Water 10(2): Article 140.

Chen, C.Y., W. Xu, Y. Dai, W. Xu, C. Liu, Q. Wu, L. Gao, and Z. Kang, et al. 2019. Household preparedness for emergency events: A cross-sectional survey on residents in four regions of China. BMJ Open 9(11): 1-9.

Chinh, D.T., P. Bubeck, N.V. Dung, and H. Kreibich. 2016. The 2011 flood event in the Mekong Delta: Preparedness, response, damage and recovery of private households and small businesses. Disasters 40(4): 753-778.

CMCC (Euro-Mediterranean Center on Climate Change). 2018. Human behavior is the key to reducing flood risk. https://www. $\mathrm{cmcc}$.it/article/human-behavior-is-the-key-to-reducing-floodrisk. Accessed 19 Feb 2019.

Dube, E., O. Mtapuri, and J. Matunhu. 2018. Flooding and poverty: Two interrelated social problems impacting rural development in Tsholotsho District of Matabeleland North Province in Zimbabwe. Jamba: Journal of Disaster Risk Studies 10(1): 1-7.

Duc, T.T., U. Tanaka, and H. Kobayashi. 2012. Living with typhoon and flood disasters: A case study in Huong Phong Commune, Tam Giang lagoon area, central Vietnam. SANSAI: An Environmental Journal for the Global Community 6: 85-96.

Eisenman, D.P., Q. Zhou, M. Ong, S. Asch, D. Glik, and A. Long. 2009. Variations in disaster preparedness by mental health, perceived general health, and disability status. Disaster Medicine and Public Health Preparedness 3(1): 33-41.

Faure, M.G. 2007. Financial compensation for victims of catastrophes: A law and economics perspective. Law \& Policy 29(3): 339-367.

Fothergill, A., and L.A. Peek. 2004. Poverty and disasters in the United States: A review of recent sociological findings. Natural Hazards 32(1): 89-110.

Grothmann, T., and F. Reusswig. 2006. People at risk of flooding: Why some residents take precautionary action while others do not. Natural Hazards 38(1): 101-120.

GSO (General Statistics Office of Vietnam). 2017. The 2017 socioeconomic situation of Vietnam. Hanoi, Vietnam: GSO.

Hartmann, T., and J. Albrecht. 2014. From flood protection to flood risk management: Condition-based and performance-based regulations in German Water Law. Journal of Environmental Law 26(2): 243-268.

Hoffmann, R., and R. Muttarak. 2017. Learn from the past, prepare for the future: Impacts of education and experience on disaster preparedness in the Philippines and Thailand. World Development 96: 32-51.

Hosseini, S.A., R. Heydari, and A. Hayati. 2013. The analysis of factors affecting people's preparedness in dealing with natural disasters in 2013 in Rasht-Iran. International Journal of Academic Research in Business and Social Sciences 3(10): 88-99.

IPCC (Intergovernmental Panel on Climate Change). 2014. Climate change 2014: Synthesis report. Contribution of Working Groups I, II and III to the Fifth Assessment Report of the Intergovernmental Panel on Climate Change, ed. Core writing team, R.K. Pachauri, and L.A. Meyer. Geneva, Switzerland: IPCC.

Kawasaki, A., G. Kawamura, and W.W. Zin. 2020. A local level relationship between floods and poverty: A case in Myanmar. International Journal of Disaster Risk Reduction 42: Article 101348 .

Kreft, S., D. Eckstein, and I. Melchior. 2016. Global climate risk index 2017. Who suffers most from extreme weather events? Weather-related loss events in 2015 and 1996 to 2015. Bonn: Germanwatch e.V. https://www.germanwatch.org/sites/german watch.org/files/publication/16411.pdf. Accessed 27 Apr 2019.

Kreibich, H., S. Christenberger, and R. Schwarze. 2011. Economic motivation of households to undertake private precautionary measures against floods. Natural Hazards and Earth System Science 11(2): 309-321.

Liu, N., X. Shao, and M. Qi. 2012. A bi-objective evacuation routing engineering model with secondary evacuation expected costs. Systems Engineering Procedia 5: 1-7.

Luo, T., A. Maddocks, C. Iceland, P. Ward, and H. Winsemius. 2015. World's 15 countries with the most people exposed to river floods. https://www.wri.org/blog/2015/03/world-s-15-countriesmost-people-exposed-river-floods. Accessed 3 Jan 2020.

Luu, C., J.V. Meding, and S. Kanjanabootra. 2018. Flood risk management activities in Vietnam: A study of local practice in Quang Nam Province. International Journal of Disaster Risk Reduction 28: 776-787.

Musiake, K. 2003. Hydrology and water resources in monsoon Asia: A consideration of the necessity of establishing a standing research community of hydrology and water resources in the Asia Pacific region. Hydrological Processes 17(14): 2701-2709.

Nguyen Duc, K., T. Ancev, and A. Randall. 2019. Evidence of climatic change in Vietnam: Some implications for agricultural production. Journal of Environmental Management 231: 524-545.

Pilarczyk, K.W., and N.S. Nuoi. 2002. Flood control and coastal protection in Vietnam. In Proceedings of the Solutions to Coastal Disasters Conference 2002, 24-27 February 2002, San Diego, California, United States, 186-204.

Poussin, J.K., W.J. Wouter Botzen, and J.C.J.H. Aerts. 2015. Effectiveness of flood damage mitigation measures: Empirical evidence from French flood disasters. Global Environmental Change 31: 74-84.

Reynaud, A., C. Aubert, and M.H. Nguyen. 2013. Living with floods: Protective behaviours and risk perception of Vietnamese households. Geneva Papers on Risk and Insurance: Issues and Practice 38(3): 547-579.

Saeed, N.A.L., N.H. Zakaria, and E. Sutoyo. 2018. Team performance in flood emergency response: A conceptual model and scale development. International Journal of Integrated Engineering 10(6). https://doi.org/10.30880/ijie.2018.10.06.006.

Sato, T. 2006. Fundamental characteristics of flood risk in Japan's urban areas. In A better integrated management of disaster risks: Toward resilient society to emerging disaster risks in megacities, ed. S. Ikeda, T. Fukuzono, and T. Sato, 23-40. Okahandja, Namibia: TERRAPUB and NIED. http://www.terrapub.co.jp/elibrary/nied/pdf/023.pdf. Accessed 7 Jul 2019.

Sayers, P., G. Galloway, E. Penning-Rowsell, Y. Li, F. Shen, Y. Chen, K. Wen, and T.L. Quesne et al. 2015. Strategic flood management: Ten "golden rules" to guide a sound approach. International Journal of River Basin Management 13(2): $137-151$.

Shaw, R. 2006. Critical issues of community based flood mitigation: Examples from Bangladesh and Vietnam. Journal of Science \& Culture 72(1): 1-17.

Skoufias, E., M. Rabassa, and S. Olivieri. 2011. The poverty impacts of climate change: A review of the evidence. World Bank Policy Research Working Paper 5622. https://doi.org/10.1596/18139450-5622.

Sørensen, J.F.L. 2014. Rural-urban differences in bonding and bridging social capital. Regional Studies 50(3): 391-410.

Thieken, A.H., M. Müller, H. Kreibich, and B. Merz. 2005. Flood damage and influencing factors: New insights from the August 2002 flood in Germany. Water Resources Research 41(12): $1-16$.

Tran, P., and R. Shaw. 2007. Towards an integrated approach of disaster and environment management: A case study of Thua Thien Hue Province, central Vietnam. Environmental Hazards 7(4): 271-282. 
Tran, P., R. Shaw, G. Chantry, and J. Norton. 2008. GIS and local knowledge in disaster management: A case study of flood risk mapping in Thua Thien Hue Province Vietnam. Disasters 33(1): 152-169.

Tyas, W.P. 2018. Living in prone flooding area: In coastal areas of Semarang. IOP Conference Series: Earth and Environmental Science 123: Article 012010.

UNDP (United Nations Development Programme). 2018. An analytical report on early recovery from Damrey Typhoon in Vietnam. New York: UNDP.

Valeriano, O.C.S., T. Koike, D. Yang, C.T. Nyunt, D.V. Khanh, and N.L. Chau. 2009. Flood simulation using different sources of rainfall in the Huong River Vietnam. Hydrological Sciences Journal 54(5): 909-917.

Vietnamese Government. 2015. Decision of the Prime Minister: Issuing the multi-dimensional approach to poverty applied for the 2016-2020 period. No. 59/2015/ QD-TTg. http://vanban. chinhphu.vn/portal/page/portal/chinhphu/hethongvanban?class_ id=1\&_page $=1 \&$ mode $=$ detail $\&$ document_id=182199. Accessed 17 Jun 2019.

WB (World Bank). 2010. Weathering the storm: Options for disaster risk financing in Vietnam (English). Washington, DC: World Bank. http://documents.worldbank.org/curated/en/ 569191468108554653/Vietnam-Weathering-the-storm-optionsfor-disaster-risk-financing-in-Vietnam. Accessed 3 Mar 2019.

Wilson, F.D. 1984. Urban ecology: Urbanization and systems of cities. Annual Review of Sociology 10: 283-307.

Wisner, B., P. Blaikie, T. Cannon, and I. Davis. 2003. At risk: Natural hazards, people's vulnerability and disasters, 2nd edn. New York: Taylor \& Francis.

Wu, G., Z. Han, W. Xu, and Y. Gong. 2018. Mapping individuals' earthquake preparedness in China. Natural Hazards and Earth System Sciences 18(5): 1315-1325.

Zevenbergen, C., W. Veerbeek, B. Gersonius, and S.V. Herk. 2008. Challenges in urban flood management: Travelling across spatial and temporal scales. Journal of Flood Risk Management 1: $81-88$. 